TRIBUTE

\section{Alternate harvest: Lessons in openness and connection}

\author{
Zeke Leonard * \\ Syracuse University
}

Special issue:

Food as a Tool for Social Change

FALK SYl Sycause

Submitted March 23, 2021 / Published online September 16, 2021

Citation: Leonard, Z. (2021). Alternate harvest: Lessons in openness and connection. Journal of Agriculture,

Food Systems, and Community Development, 10(4), 11-14. https://doi.org/10.5304/jafscd.2021.104.016

Copyright (C) 2021 by the Author. Published by the Lyson Center for Civic Agriculture and Food Systems. Open access under CC-BY license.

\title{
Abstract
}

This tribute remembers a dear friend and valued colleague through a project that we did together.

\section{Keywords}

Tribute, Harvest, Space-Making

$\mathrm{O}$

$\mathrm{n}$ a summer day in 2012, I got a call from Evan Weissman telling me that a tree had fallen in the community garden that he helped found in our neighborhood. He knew that as a furniture designer and maker, I would have an interest in it.

As we stood and looked at it, we started to talk about possibilities, which of course, was a special skill of Evan's. This tree, an inconvenience in its current state, had a different identity to me as a furniture designer and maker: I commented on the fact that the trunk was straight enough that there might be good lumber in it and that we shouldn't simply chip it for mulch and buck it for firewood. Instead, we could work with garden members to treat it as any other garden offering: something to be harvested. Instead of food, however, the tree would yield material that could activate the garden as a public space (see Figure 1).

This idea of harvest as being relevant in non-food contexts was one that Evan and I shared. In a way, it is really a method of examining value constructs through the lens of praxis. Bernard Tschumi, one of

** Zeke Leonard, Assistant Professor, Syracuse University College of Visual and Performing Arts, Syracuse, NY USA;

+1-917-903-0604; mleona02@syr.edu 
the most influential architectural theoreticians, reminds us in his book Event/Cities: Praxis that praxis (as contrasted with practice) is identified by being constantly held accountable to those who, by using the space, will activate it (Tschumi, 1994).

It is this activation that has the power to shock us into rethinking existing value constructs: a weedy vacant lot is a potential source for community building and food production; a storm-felled tree is a potential furniture object to invite the community in; the act of designing and making that furniture is a potential intersection point for community members interested in creating positive change. The first step, of course, is to be open to recognizing these potentialities.

This eye for potential value was one of Evan's great gifts to all of us that worked or

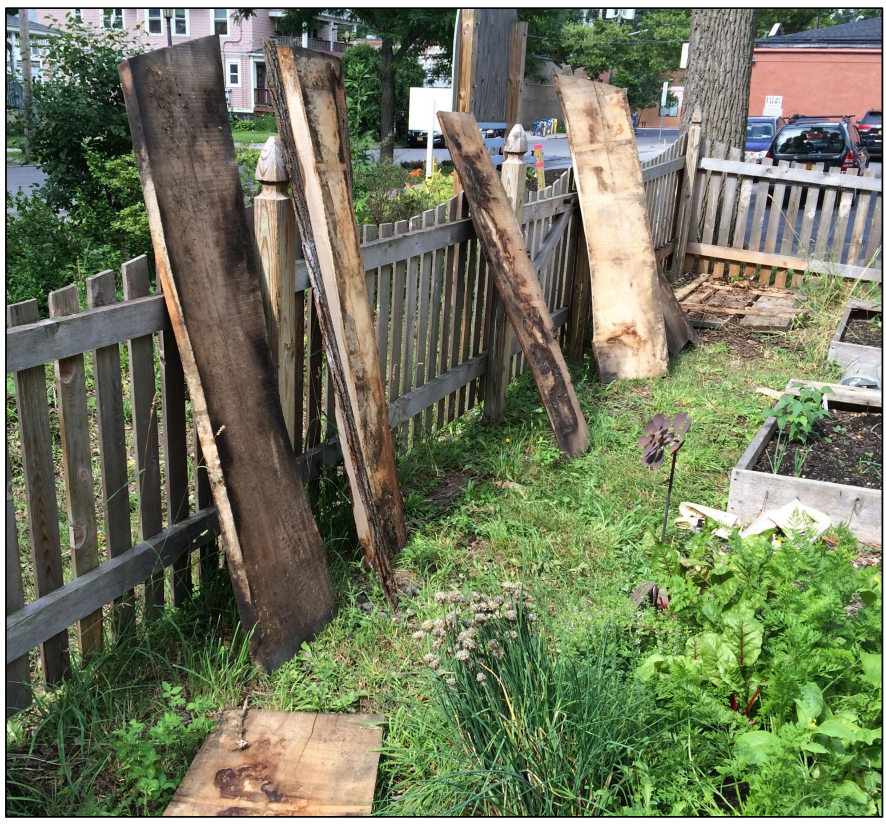

Figure 1. Maple planks leaning against the fence of the community garden. played with him. I will remember him as being an especially open person in many facets of his life. What, after all, could a design professor offer to the academic scholarship of a food studies professor? As it turned out, we had quite a bit of overlap.

An article we were working on when he died pointed out that "community gardens necessarily engage in "resources responsive" design"; that is, that what is enacted in the space tends to be directly driven by its cost, either in dollars raised by members or in hours given as volunteers to the garden. Typically, in this kind of environment, any design process is engaged in an ad hoc process. For example, community gardeners will encounter a need for raised beds (due to contaminated soil, poor soil, or no soil), and the response is driven by a functional reality. "Design," in a formal sense, tends to emerge organically based on resources available, including human capital (labor and knowledge), environmental conditions, finances, etc.

Among the challenges facing this particular community garden was the navigation of "public" space available to passersby and "semi-private" space intended for use by the gardeners themselves. The gardeners had installed a public bed outside the fence around the garden as an invitation to the public to enjoy some of the fruits of their labor and inhibit theft, which was an ongoing problem. Evan brought up that it also made sense to create a public gathering spot, especially given the garden's proximity to a popular coffee shop and shopping district.

In collaboration with other garden members, we spent a couple of July Saturdays surfacing the lumber, cutting it to length, and using an inclusive, consensus-based process to design, build, and install a bench adjacent to the sidewalk, one that everyone walking by the garden would be able to use. This would be a bench that allowed the sitter to look inward to the garden or outward to the street. They could perch only for a moment or could lean back against the birch tree that the bench was built around, enjoying a summer afternoon and a cup of coffee (see Figure 2).

As we worked together with other gardeners to examine the shapes of the planks, to use the tools that surfaced them and drilled holes and installed hardware, I had the opportunity to watch Evan's deft hand with managing diverse voices and skillsets within a project. He worked with the cheerfulness and 


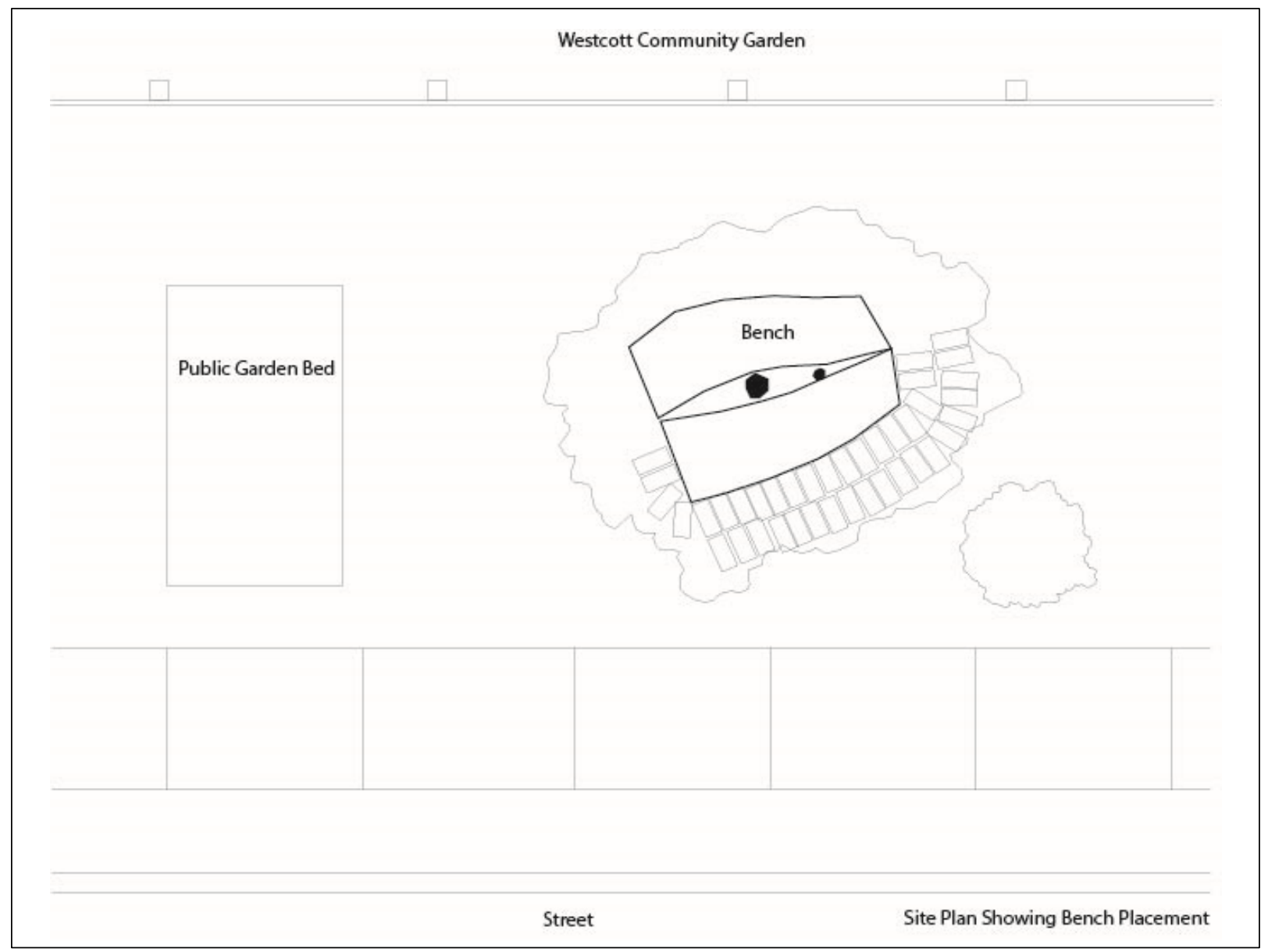

Figure 2. Diagram of the location of the bench.

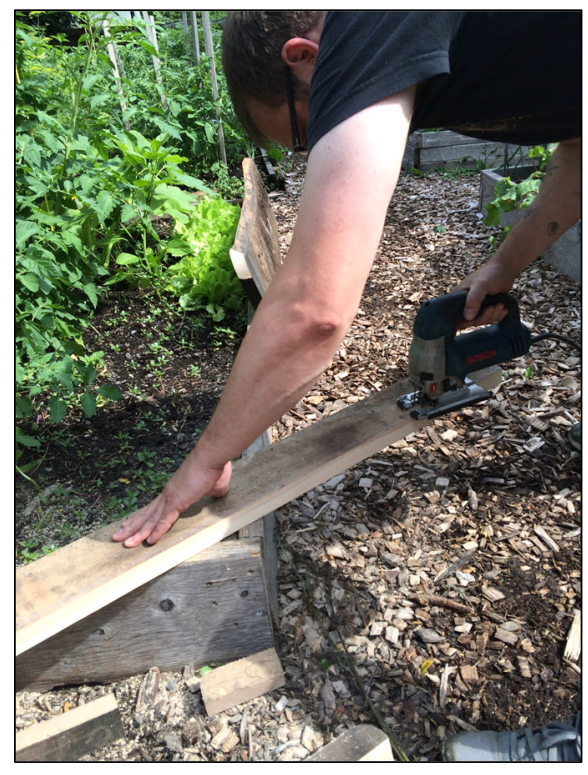

Figure 3. Evan working on the bench in the community garden. skill that we were so used to, being present in both the design and building processes (see Figure 3).

This was not by far the only project that we worked on together. Still, it was a memorable one for me, as it was a true intersection of our academic lives, overlaid onto our social lives in a way that was very much how I remember Evan: connections and overlaps were prevalent. Openness to possibility and a willingness (even a desire) to be right in the heart of everything were so central to his way of moving through life.

Harvest in this project had wide-ranging applications: we could harvest lumber from the tree, energy and involvement from the gardeners, and skill and expertise from Evan and myself. The yield was (and is) profound. I walk by this bench frequently (Figure 4), and it has become an unintentional memorial for me, a place that I can commune with Evan through an object that we both brought into being and placed in situ in a space that was also the fruit of labor of himself, his family, friends, and colleagues. 


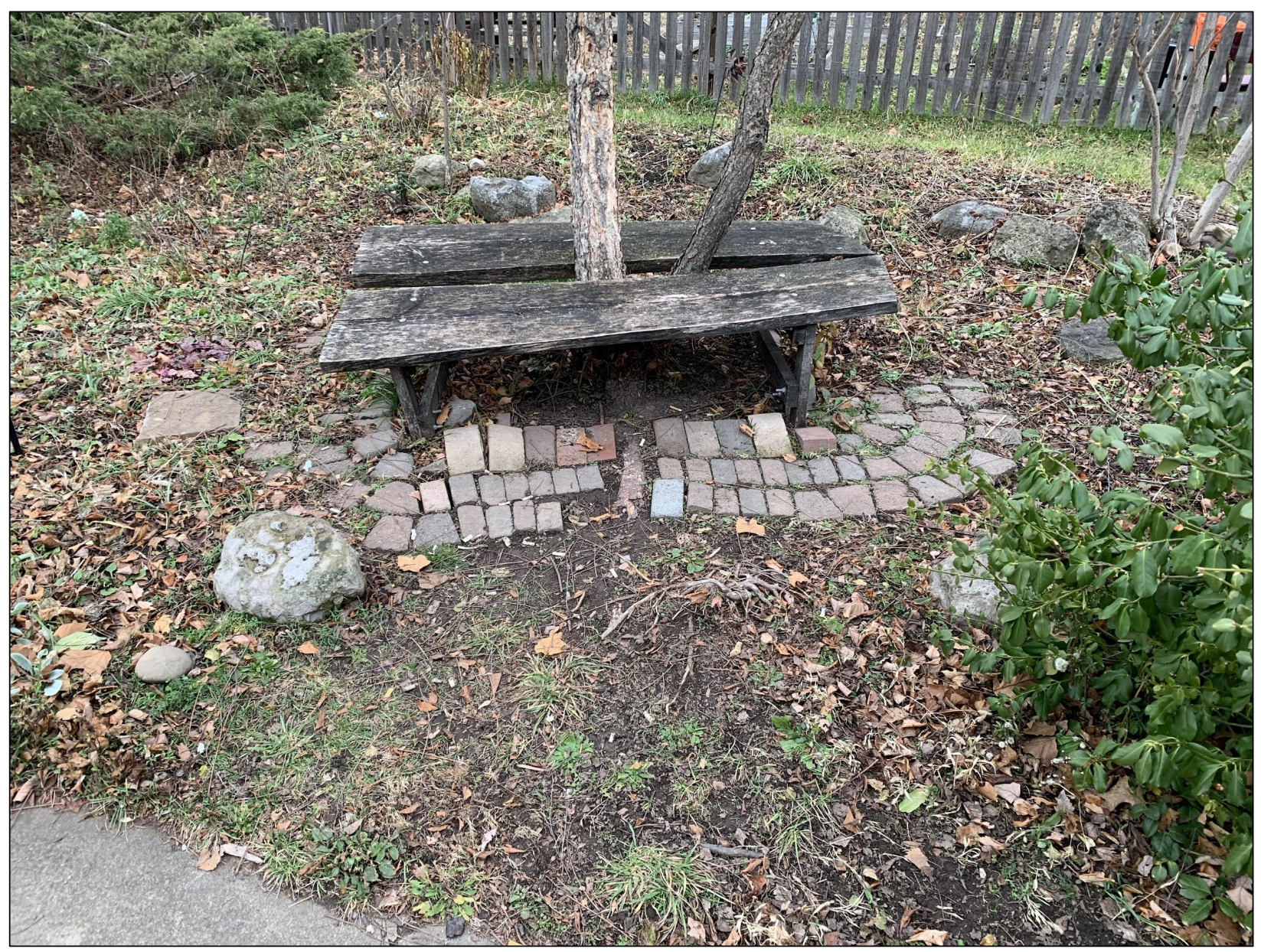

Figure 2. The finished bench in situ.

\section{Reference}

Tschumi, B. (1994). Event/Cities (Praxis). MIT Press. 